\title{
Evaluation of health literacy and resources to achieve them among librarians of Mazandaran public library
}

\author{
A. Mousavi Chalak ${ }^{1}, \underline{\text { A. Riahi }}{ }^{2}$ \\ ${ }^{1}$ Department of Knowledge and Information Science, Payame Noor University, Tehran, Iran \\ ${ }^{2}$ Knowledge and Information Science Graduated, Tehran University, Tehran, Iran \\ Corresponding Address: Aref Riahi, Department of Knowledge and Information Science, Tehran University, Tehran, Iran \\ Tel: +98-930-9177068, Email: Ariahi1986@gmail.com \\ Received: 3 Jun 2017; Accepted: 15 Jul 2017
}

* Abstract

Background: It seems to be important and necessary for librarians to develop and promote their own health information and increase their own health literacy which they play a great role in this subject in society.

Objective: The aim of this study is measuring of health literacy and resources to achieve them among librarians of Mazandaran public library.

Methods: This is applied and survey-descriptive study in 2017. Statistical population include 147 librarians and staff of Mazandaran public library foundation. To collect data, we used TOFHLA questionnaire and none-Para metrics test to analysis data.

Findings: Findings show that most of librarians 125 subjects (85\%) have suitable health literacy. Audio and video media and doctors were founded as the most important facilities to access to health information among them. Moreover, there were positive correlation between "health literacy of librarians" and "use video-audio media", "relationship with doctors", "use internet", "use social networks", and "participate to educational courses related to health and hygiene ( $r=0.41, r=0.37$, $\mathrm{r}=0.29$, $\mathrm{r}=0.22$, and $\mathrm{r}=0.26$ ) respectively.

Conclusion: Attention to the resources related to health information will improve quality of health literacy. Planning and making policy by public library foundation, Ministry of Health, government and coordination with other organizations will provide positive impacts for health literacy of librarians' society.

Keywords: Health literacy, Health information seeking, Health information, Librarian, Public library, Mazandaran

Citation: Mousavi Chalak A, Riahi A. Evaluation of health literacy and resources to achieve them among librarians of Mazandaran public library. J Qazvin Univ Med Sci 2018; 21 (6): 64-73. 


\title{
سواد سلامت و منابع كسب آن در ميان كتابداران كتابخانههاى عمومى استان مازندران
}

\author{
دكتر افشين موسوى خلك'، عارف رياحى؟
}

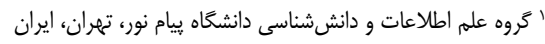

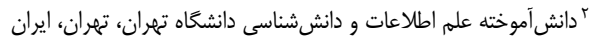

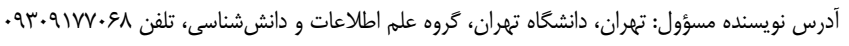
تاريخ دريافت: س/

زمينه: گَسترش و توسعه آكَاهى و اطلاعات در زمينه بهداشت و سلامت و ارتقاى سواد سلامت براى كتابداران كه خود نقش مهمى در تحقـق سـواد

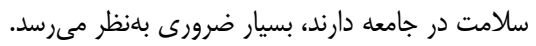
هدف: مطالعه حاضر با هدف بررسى سواد سلامت و منابع كسب آن در ميان كتابداران كتابخانههاى عمومى استان مازندران صورت گرفرت.

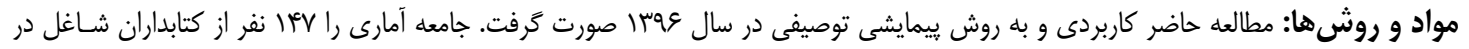

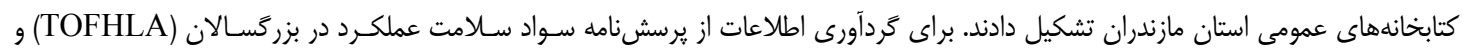

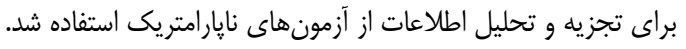

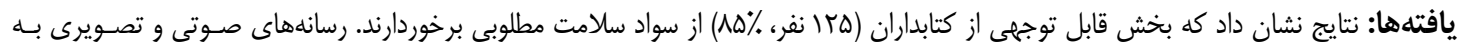

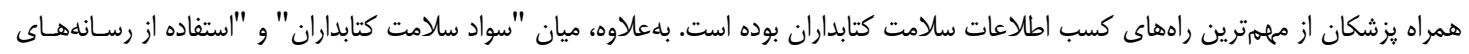

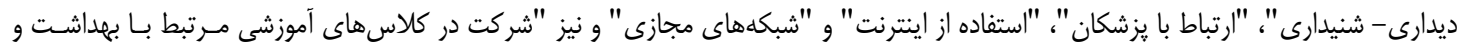

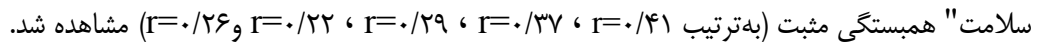

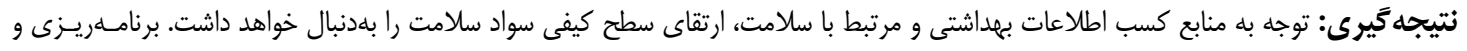

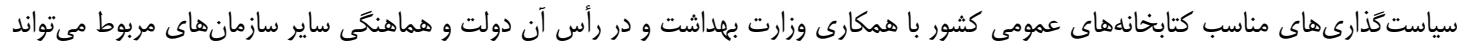

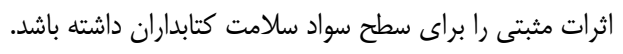

كليدوازهها: سواد سلامت، اطلاعيابى سلامت، اطلاعات سلامت، كتابداران، كتابخانههاى عمومى، مازندران

豖

سلامت نه فقط بهعنوان يك ويزگى و عامل فردى، بلكـهـ

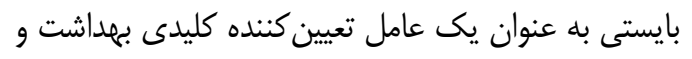

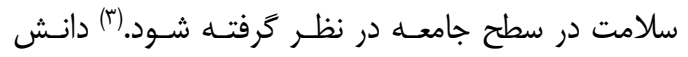
ناكافى در مورد يك مسئله بهداشتى خاص به سبب سـواد

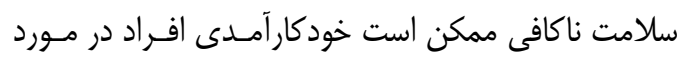

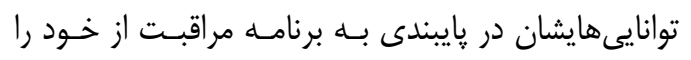

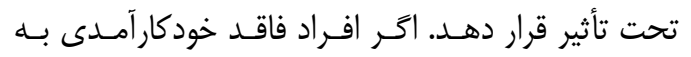
تصميمات خود يايبند نباشند، نمىتوانند بلهور مناسبسى از
بنا به تعريف، سواد سـامت عبـارت اسـت از ميـزان ظرفيت فرد براى كسب، درك و تفسير اطلاعـات اوليـه و خدمات سلامتى كـه بــراى تصـميهم گيـرى متناسـب لازم

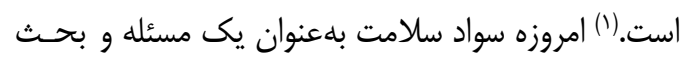
جهانى معرفى شده است و بر اين اساس، سازمان جهـانى

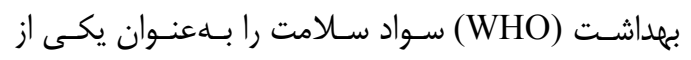
بزرگترين عوامل تعيين كننده امر سلامت معرفى نمـوده است.(ז) همرجنين ايـن سـازمان اعـلام داشـته كـه سـواد 


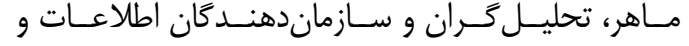

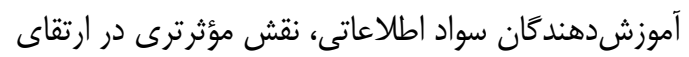

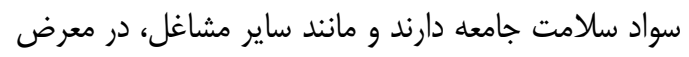

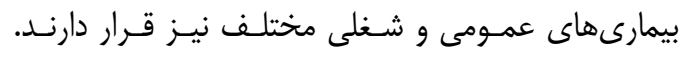

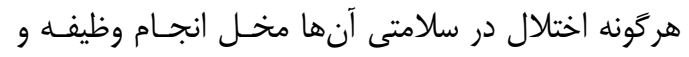

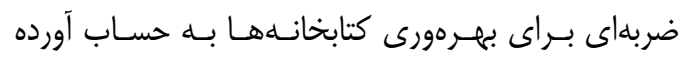

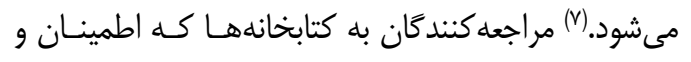

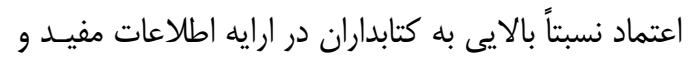

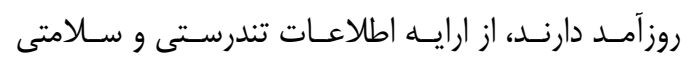

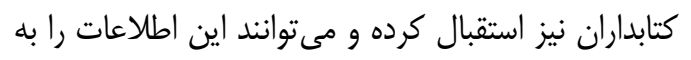

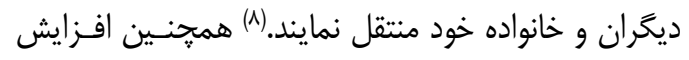

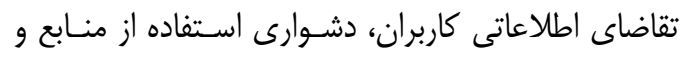

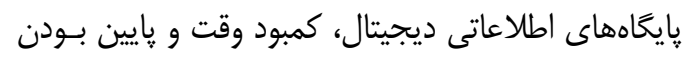

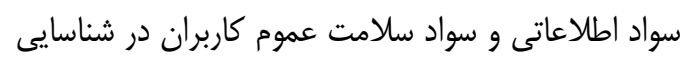
اطلاعات معتبر، نياز به متخصصانى را كه بتوانند به آنهـا

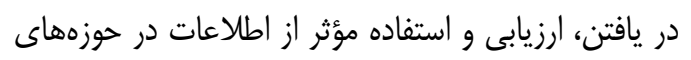
مختلف سلامت كمى كنند، ضرورى مىنمايد. (9.

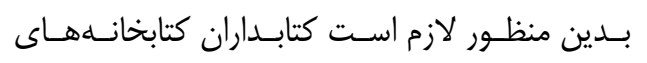

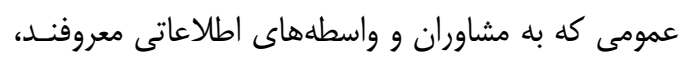

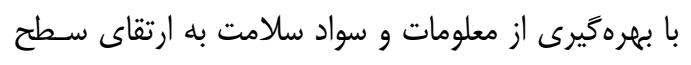

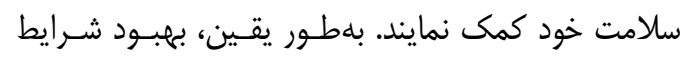

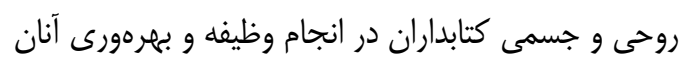

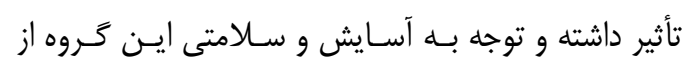

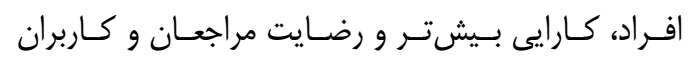
كتابخانهها را به همراه خواهد داشت. بنابراين ارزيابى سواد

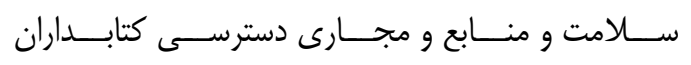
كتابخانههاى عمومى به اطلاعات بهداشـتى و مـرتبط بــا سلامت لازم و ضرورى به نظر مىرسد. يزوهشهاى مختلفى در ايران و جهان در رابطه با سواد

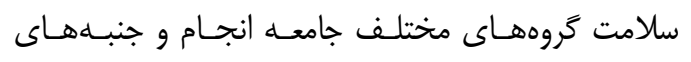

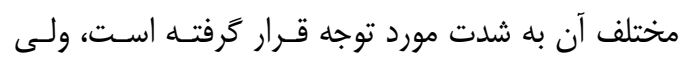

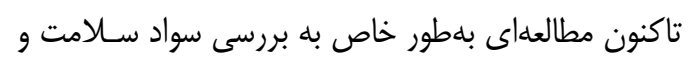

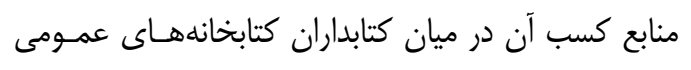

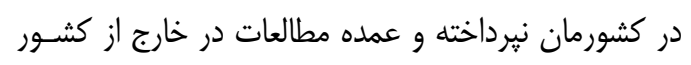

خود مراقبت كنند.(*)

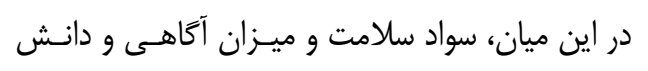

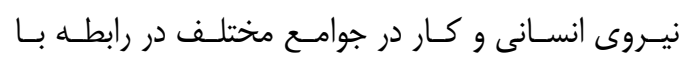

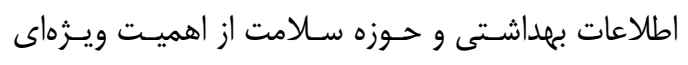

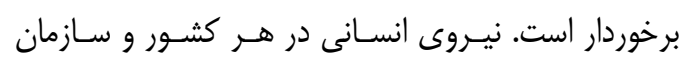

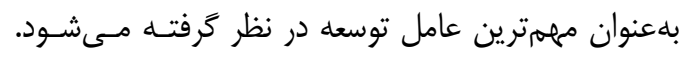

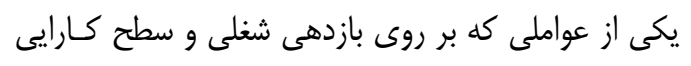

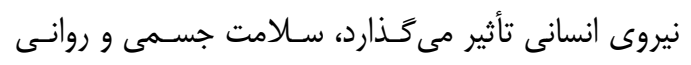

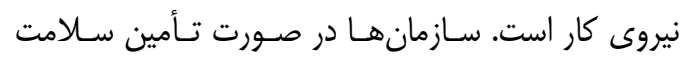

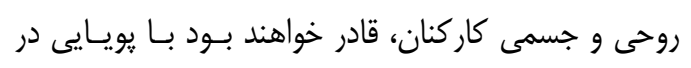
جهت رسيدن به سطوح بالاترى از بهرهورى قدم بردارنسـ.

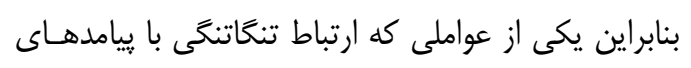

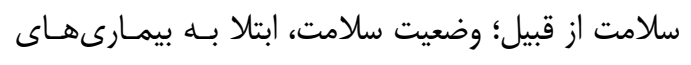

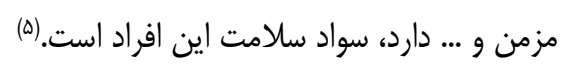

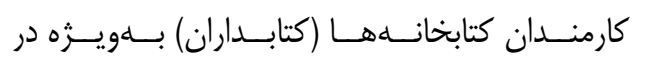

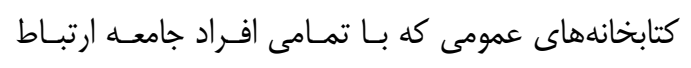

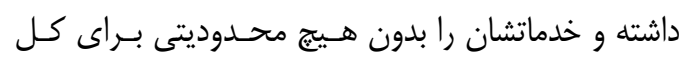

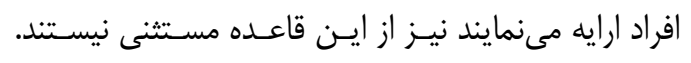

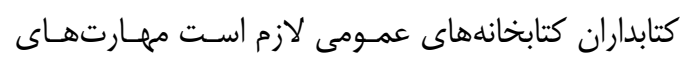

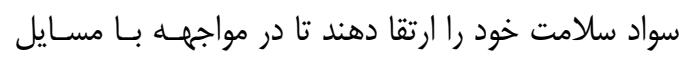
بهداشتى، درمانى و مرتبط با سلامت بهويـزه بيمـارى دهــا،

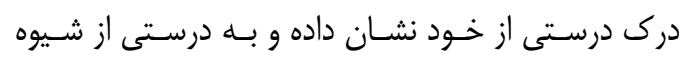

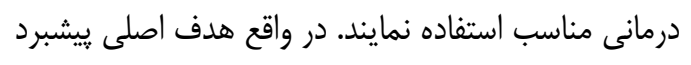
سواد سلامت براى افراد، تسـهيل راهبــرد ارتبـاطى مـؤثر بهداشتى بلمنظور ييامدهاى سلامتى، كيفيت مراقبتهاى بهداشتى و دستيابى به سطح سلامت مطلـوب و مناسـب بلـي

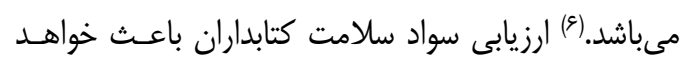

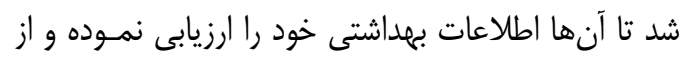

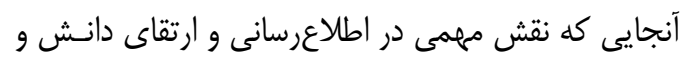

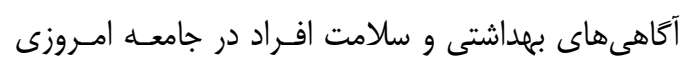

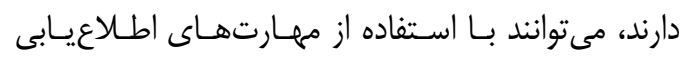

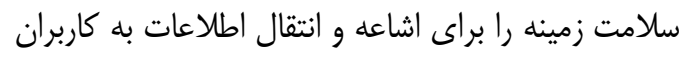

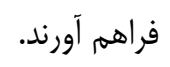
كتابداران كتابخانههاى عمومى بلهعنوان جستجو گران 
نظير ميزان آشنايى با زبان انخليسى و وضـعيت سـلامتى

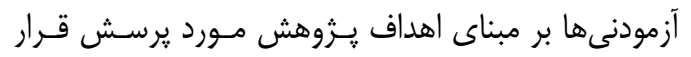

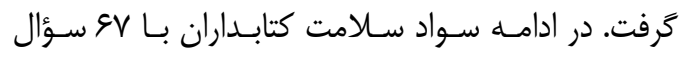

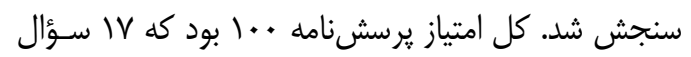

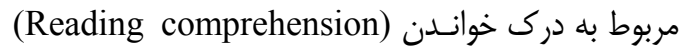

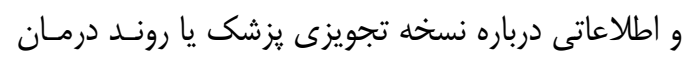

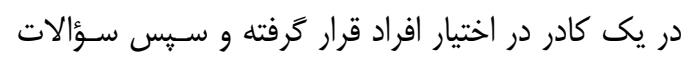

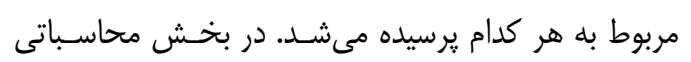

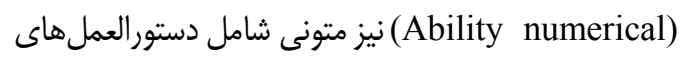

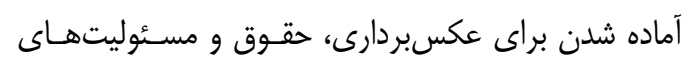

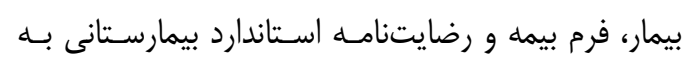
صورت متونى با وازههاى حذف شده در اختيار افـراد قـرار

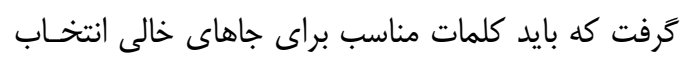

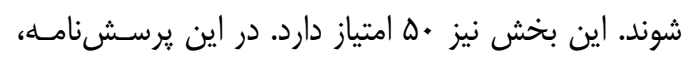

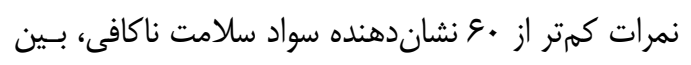
.

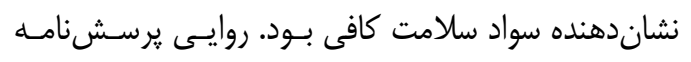

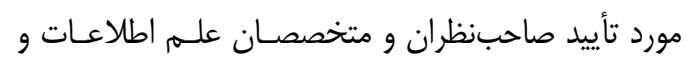

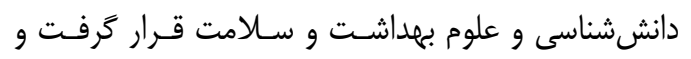

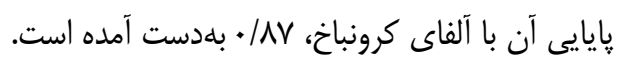

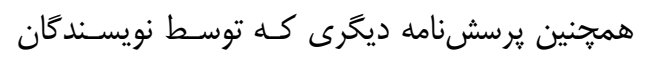
تهييه شده است، جهـت بررسـى منـابع كسـب اطلاعـات

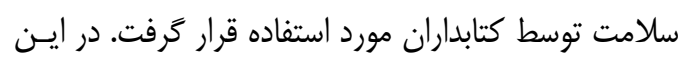

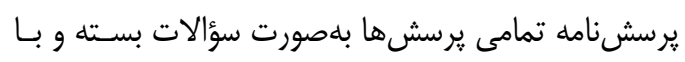

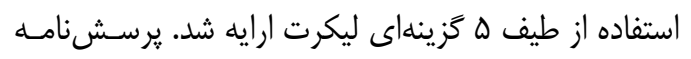

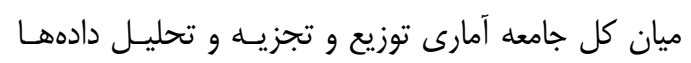

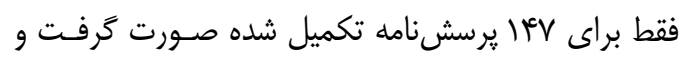

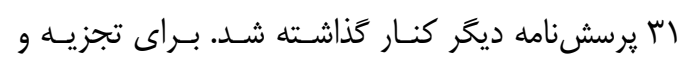

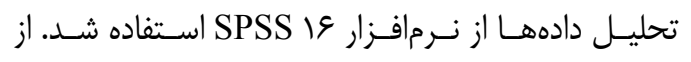

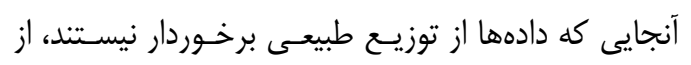

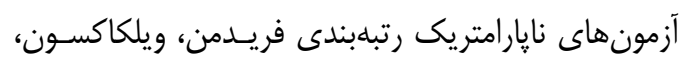

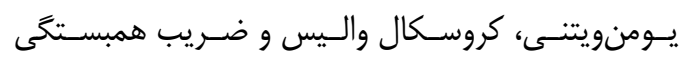
اسبيرمن استفاده شده است. كروسئ

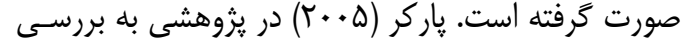

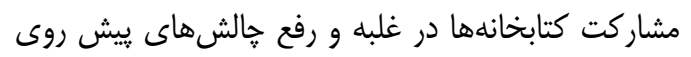
سواد سلامت يرداخته و بر اهميت سواد سلامت كتابداران جهت ترويج اطلاعات سلامت به كاربران كتابخانه تأكيـد

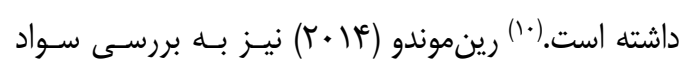

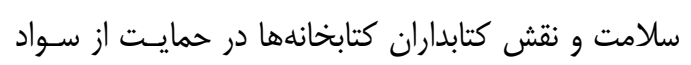

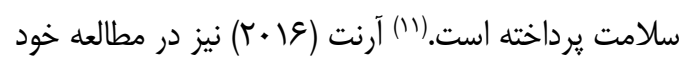
به اهميت سواد سلامت براى كتابداران و نقش ذاتى آنها

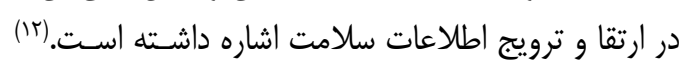

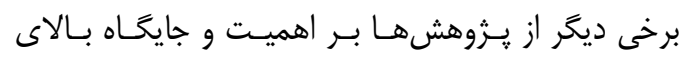

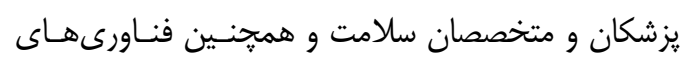

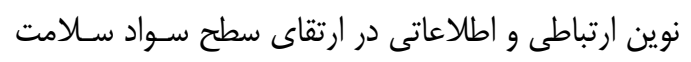

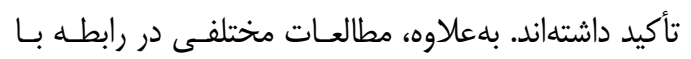

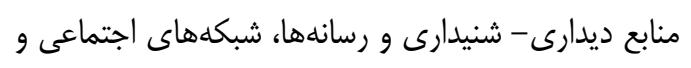

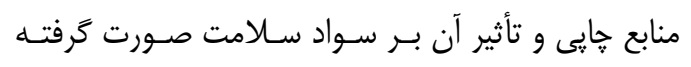

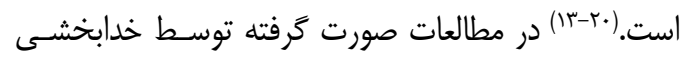

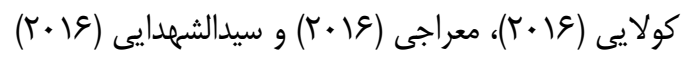

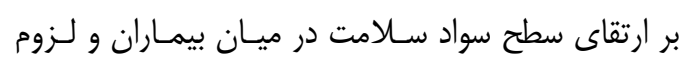
دسترسى آنها به اطلاعات بهداشتى از طريق منابع جايى إنى

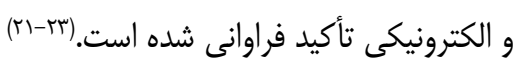
با توجه به مطالب ارايه شده، هدف از مطالعـه حاضـر،

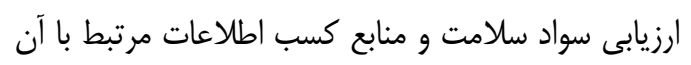
در ميان كتابداران كتابخانههاى عمومى اسـتان مازنسـران

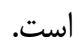

\section{مواد و روشها:}

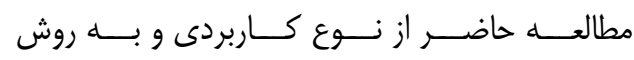

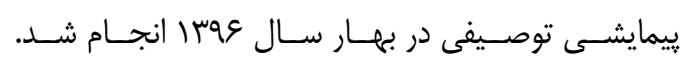

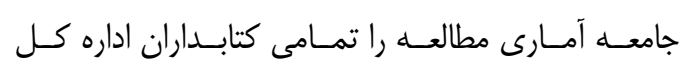

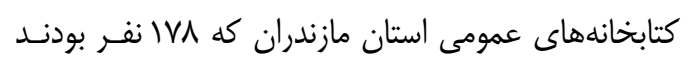

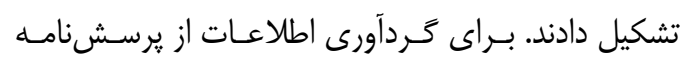

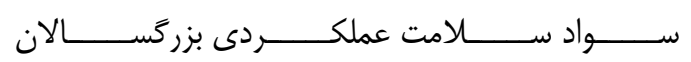
(TOFHLA: Test of Functional Health Literacy of Adults) استفاده شد.(TF) ويزگى هاى جمعيتشناختى و نيز مـواردى 
جدول ا - وضعيت سواد سلامت كتابداران مورد بررسى

\begin{tabular}{|c|c|c|}
\hline درصد & ت تعداد & سطح سواد سلامت \\
\hline$\Delta / \Delta$ & $\wedge$ & ناكافى \\
\hline $9 / \Delta$ & $1 f$ & مرزى \\
\hline$\Lambda \Delta$ & ITD & كافى \\
\hline
\end{tabular}

براى مقايسه ميانخين رتبههاى مربوط بــه استفاده از

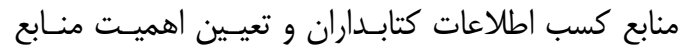

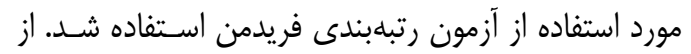

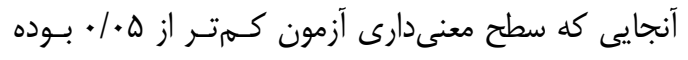

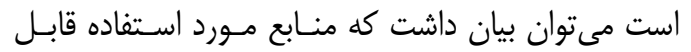

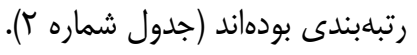
يافتهها نشان داد كه همبستخى مثبت و معنى دارى

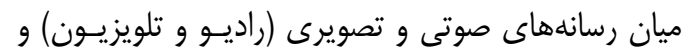
سواد سلامت و همجنين سطح سـواد سـلامت كتابــاران مورد بررسى وجود داشته است. در جدول س، ارتباط ميـان

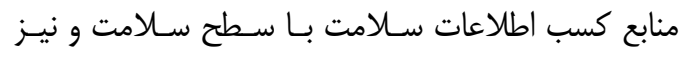

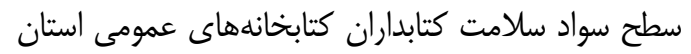

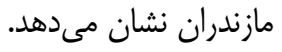

(1) يافتهها:

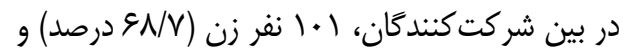

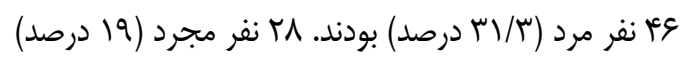

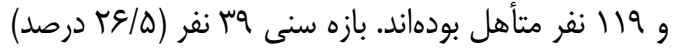

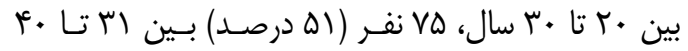

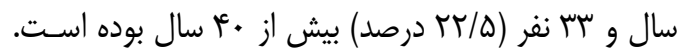

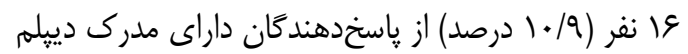

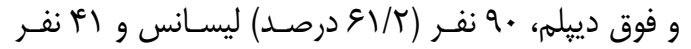

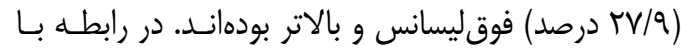

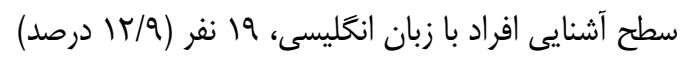

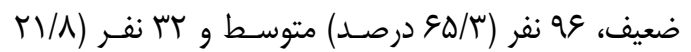
درصد) خوب و از لحاظ وضعيت سلامتى بلترتيـب 1 نفـر

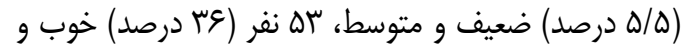

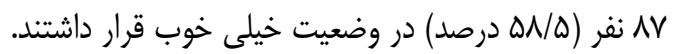

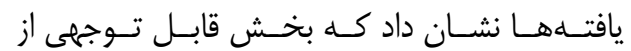
ياسخدهندكان داراى سواد سلامت كافى بودهاند. همجنين

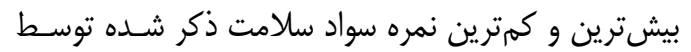

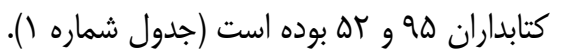

جدول r- مقايسه ميانكين رتبه منابع كسب اطلاعات سلامت در ميان كتابداران مورد مطالعه

\begin{tabular}{|c|c|c|c|c|}
\hline $\begin{array}{c}\text { P } \\
\text { P }\end{array}$ & $\begin{array}{c}\text { درجه آزادى } \\
\text { df }\end{array}$ & $\begin{array}{c}\text { مجذور خى } \\
X^{2}\end{array}$ & ميانكين رتبه & 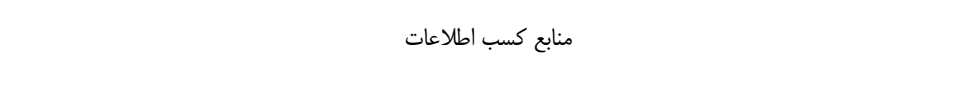 \\
\hline \multirow{10}{*}{. } & \multirow{10}{*}{9} & \multirow{10}{*}{$r F r / \cdot 9$} & $\mathrm{v} / \mathrm{vq}$ & رسانههاى صوتى و تصويرى (راديو و تلويزيون) \\
\hline & & & $V / \cdot \Delta$ & يزشى معالج \\
\hline & & & $8 / 1$. & 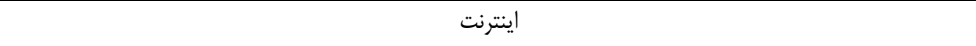 \\
\hline & & & s/re & 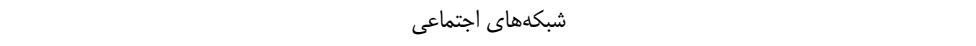 \\
\hline & & & ه/q & منابع اطلاعاتى خايى شامل؛ كتاب، نشريه، روزنامه و ... \\
\hline & & & $\Delta / 99$ & افراد خانواده \\
\hline & & & $F / r)$ & 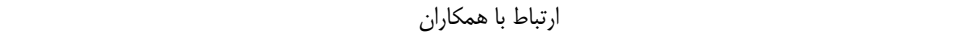 \\
\hline & & & $F / 1 \Lambda$ & دوستان و آشنايان \\
\hline & & & $r / M$ & ارتباط با افراد شاغل در مراكز بهداشتى، بيمارستانى، داروخانههاو ...از قبيل؛ يرستار ان، بهياران، كارمندان مراكز بهداشتى و... \\
\hline & & & $r / \Delta r$ & شركت در دورههاى آموزشى مربوط به اطلاعات يزشكى، بهداشتى و سلامت \\
\hline
\end{tabular}




\section{جدول بـ- همبستكى ميان منابع كسب اطلاعات سلامت با سطح سلامت و نيز سواد سلامت كتابداران استان مازندران}

\begin{tabular}{|c|c|c|}
\hline سطح سواد سلامت & سطح سلامت & منابع كسب اطلاعات سلامت \\
\hline $\begin{array}{c}\mathrm{r}=0.41 \\
\mathrm{P}=0.03\end{array}$ & $\begin{array}{l}r=0.34 \\
P=0.04\end{array}$ & رسانهاى صوتى و تصويرى (راديو و تلويزيون) \\
\hline $\begin{array}{c}\mathrm{r}=0.37 \\
\mathrm{P}=0.035\end{array}$ & $\begin{array}{c}\mathrm{r}=0.51 \\
\mathrm{P}=0.021\end{array}$ & 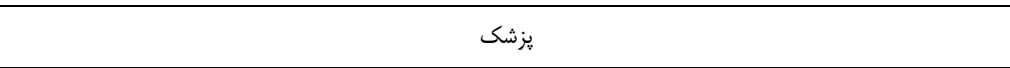 \\
\hline $\begin{array}{c}\mathrm{r}=0.29 \\
\mathrm{P}=0.05\end{array}$ & $\begin{array}{c}\mathrm{r}=0.21 \\
\mathrm{P}=0.055\end{array}$ & 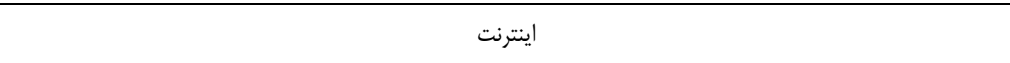 \\
\hline $\begin{array}{c}\mathrm{r}=0.22 \\
\mathrm{P}=0.31\end{array}$ & $\begin{array}{c}\mathrm{r}=0.19 \\
\mathrm{P}=0.14\end{array}$ & 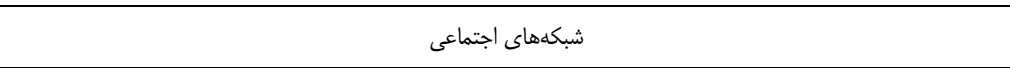 \\
\hline $\begin{aligned} \mathrm{r} & =0.23 \\
\mathrm{P} & =0.045\end{aligned}$ & $\begin{array}{l}\mathrm{r}=0.09 \\
\mathrm{P}=0.07\end{array}$ & منابع اطلاعاتى قايى شامل؛ كتاب، نشريه، روزنامه و ... \\
\hline $\begin{array}{c}\mathrm{r}=0.18 \\
\mathrm{P}=0.16\end{array}$ & $\begin{array}{l}\mathrm{r}=0.11 \\
\mathrm{P}=0.31\end{array}$ & افراد خانواده \\
\hline $\begin{array}{l}\mathrm{r}=0.11 \\
\mathrm{P}=0.36\end{array}$ & $\begin{array}{l}\mathrm{r}=0.06 \\
\mathrm{P}=0.11\end{array}$ & ارتباط با همكاران \\
\hline $\begin{array}{l}r=0.20 \\
P=0.23\end{array}$ & $\begin{array}{c}\mathrm{r}=0.24 \\
\mathrm{P}=0.08\end{array}$ & ارتباط با افراد شاغل در مراكز بهداشتى، بيمارستانى، داروخانهها و ... از قبيل؛ يرستاران، بهياران، كارمندان مراكز بهداشتى و ... \\
\hline $\begin{array}{l}\mathrm{r}=0.26 \\
\mathrm{P}=0.03\end{array}$ & $\begin{aligned} \mathrm{r} & =0.17 \\
\mathrm{P} & =0.048\end{aligned}$ & شر كت در دورههاى آموزشى مربوط به اطلاعات بز شكى، بهداشتى و سلامت \\
\hline
\end{tabular}

سلامت، نقش ويزه و تعيين كنندهاى را ايفـا مسى كنتـد. در

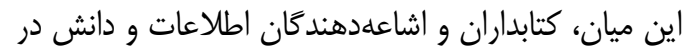

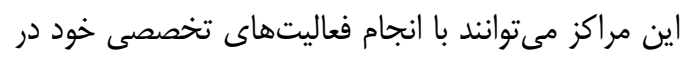

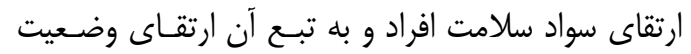

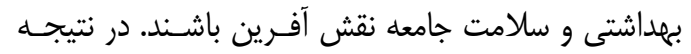

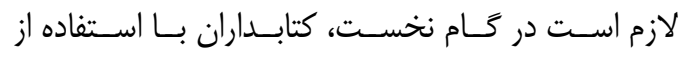

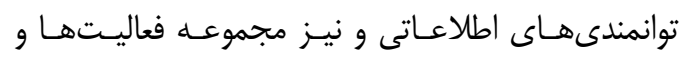

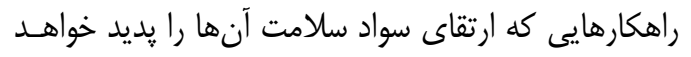

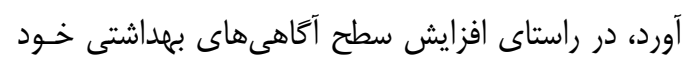

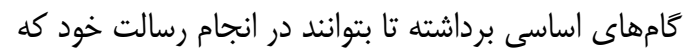

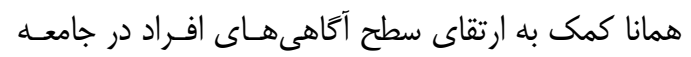
است، نقش آفرين باشند.

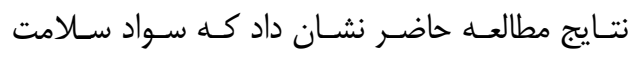

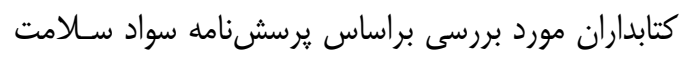

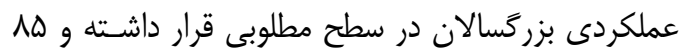

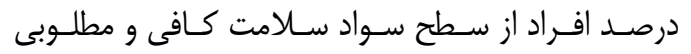

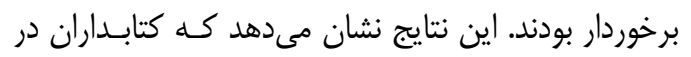
مقايسه با ساير افراد جامعه، از سطح سواد سلامت بالاترى

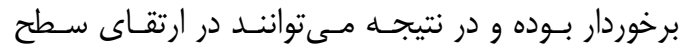

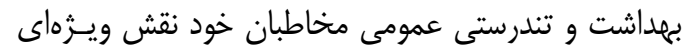

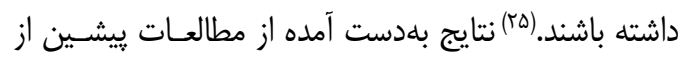

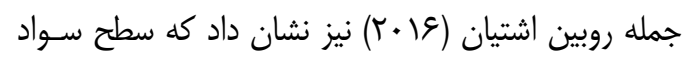

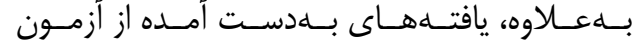

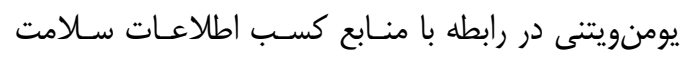

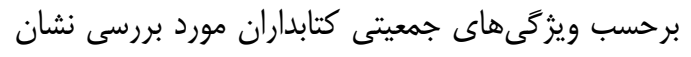

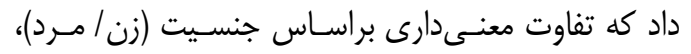

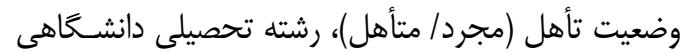

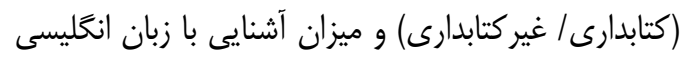

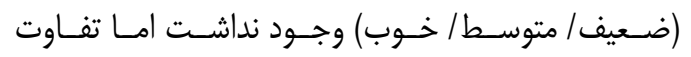

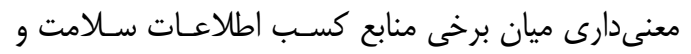

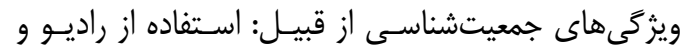

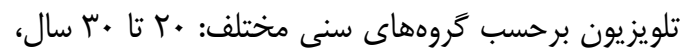

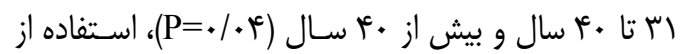

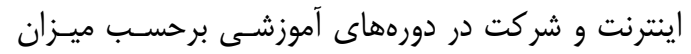

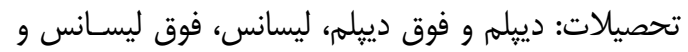

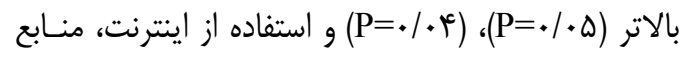

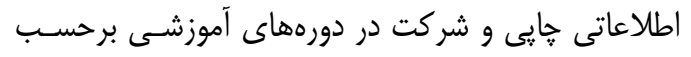

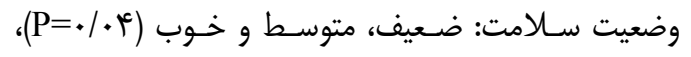
(P=•/.•)

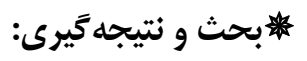

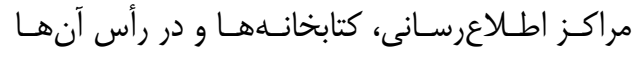

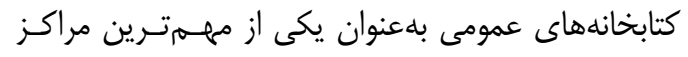

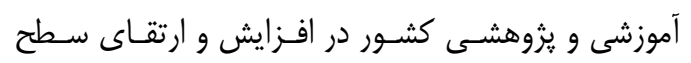

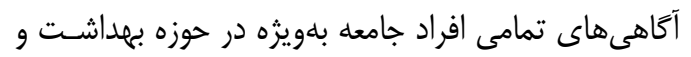


افراد بدون محدوديتهاى زمانى و مكانى مؤثر واقع شود.

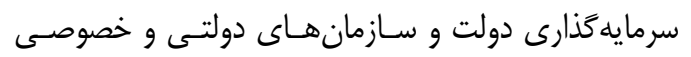

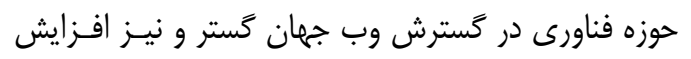

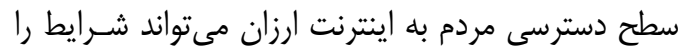
براى كسب اطلاعات سلامت فراهم سازد.

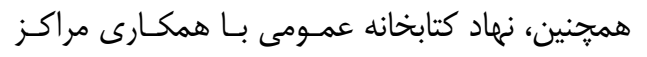

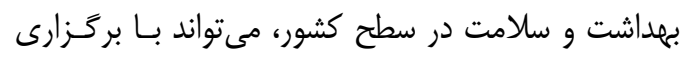

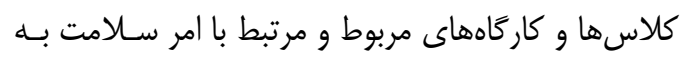

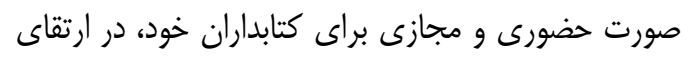

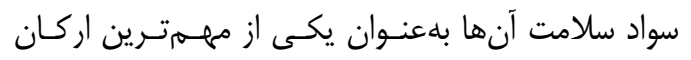

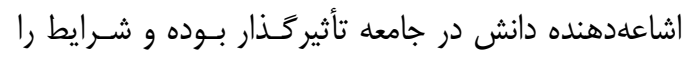

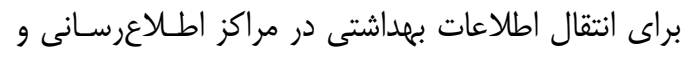

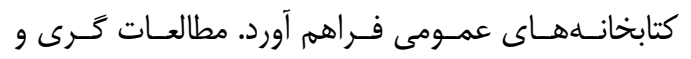

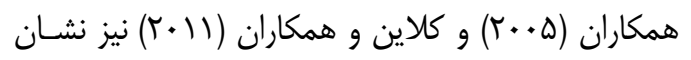

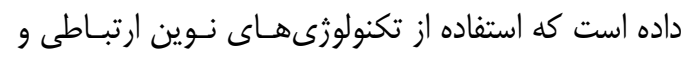

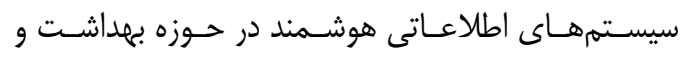

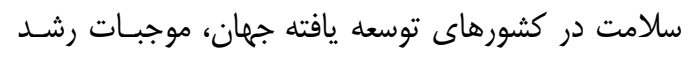

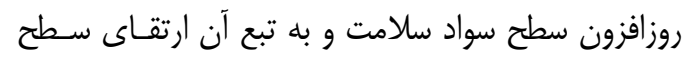

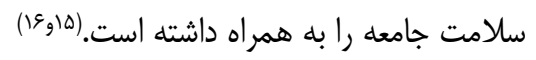

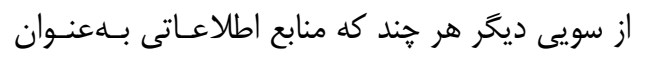
يكى از مهمترين مجارى كسب اطلاعات سلامت افراد در

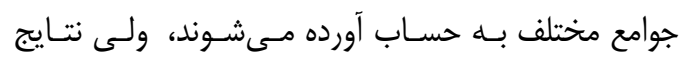
مطالعه حاضر نشان داد كه اين منابع در مقايسه بـا سـاير

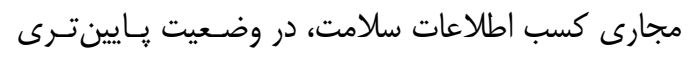

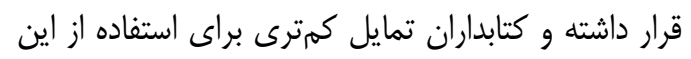

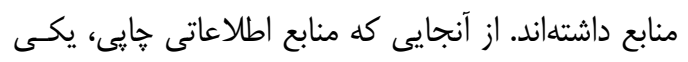

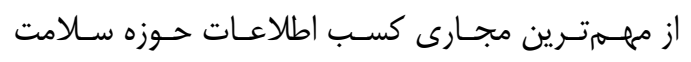

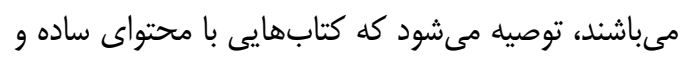

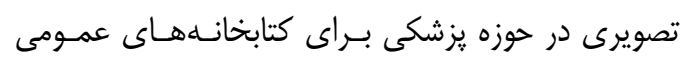

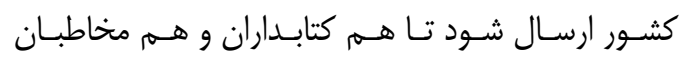

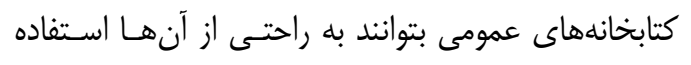

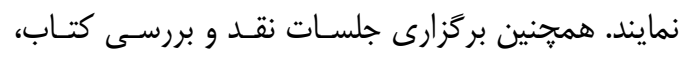

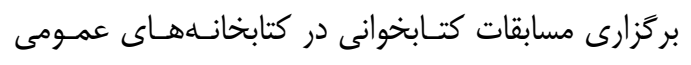

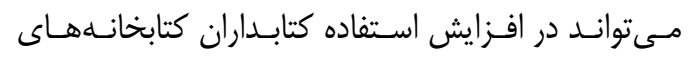

سلامت كتابداران كتابخانههـا نسـبتاً مطلـوب بـوده و بــاــا يافتهاى مطالعه حاضر، همسو و همراستا مىباشد. (؟؟)

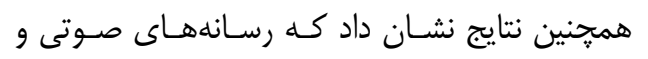

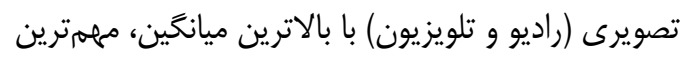

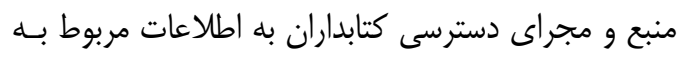

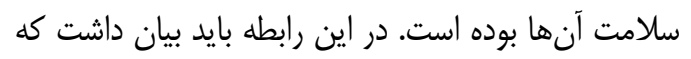

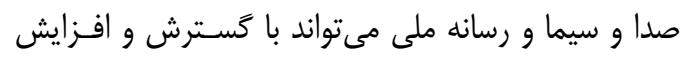

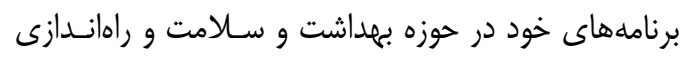

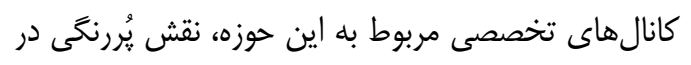

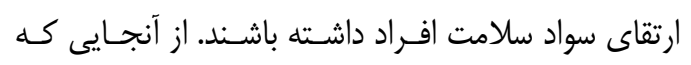

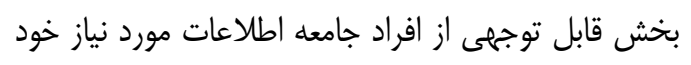

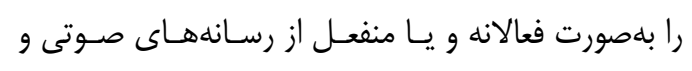

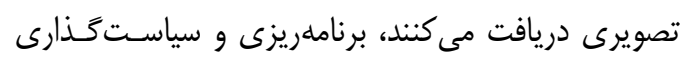

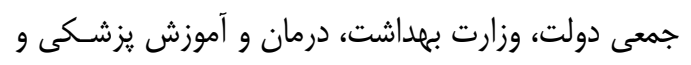
رسانه ملى مىتواند كمى شايانى به اين امر نمايد. نتـايج بسيارى از مطالعات ييشين از جمله؛ صحرايى و همكـاران

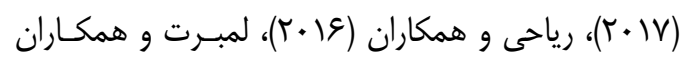

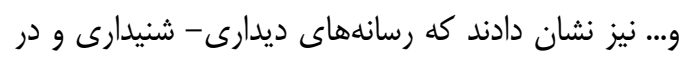

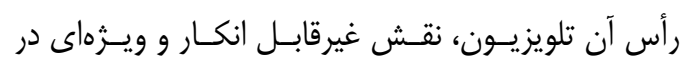

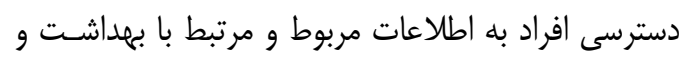

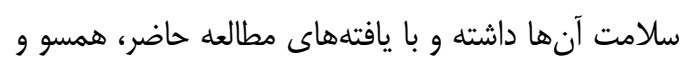

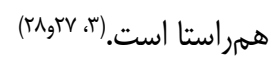

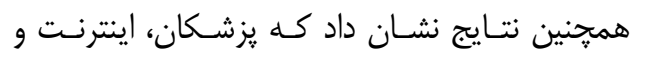
شبكههاى اجتماعى، از ديخر مجارى دسترسـى كتابــاران

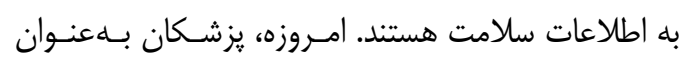
يكى از مههترين اجزاى نظام بهداشت، سلامت و درمـان

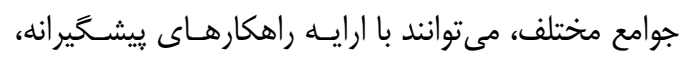

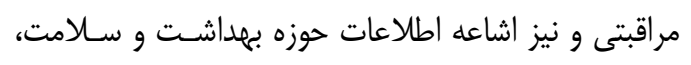

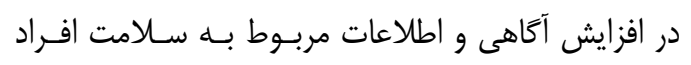

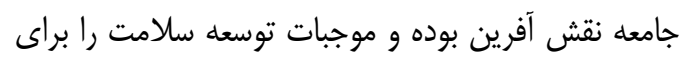

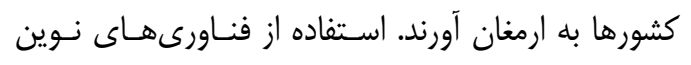

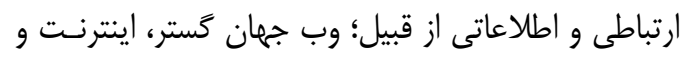

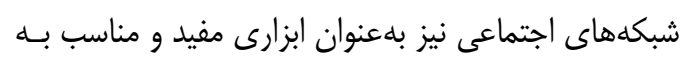

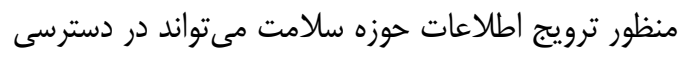




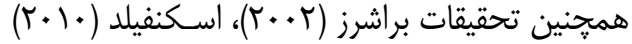

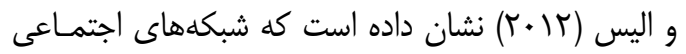

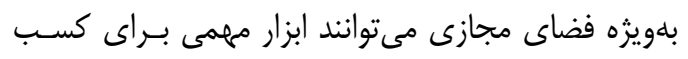

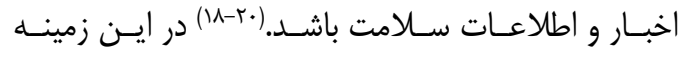

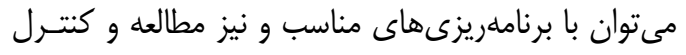

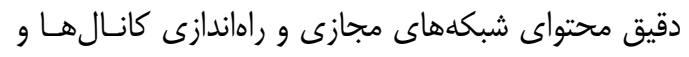

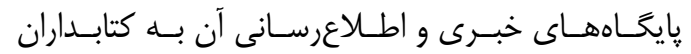

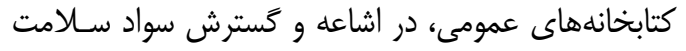

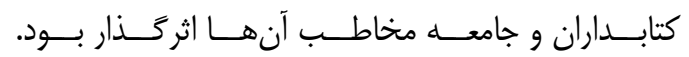

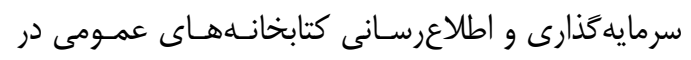

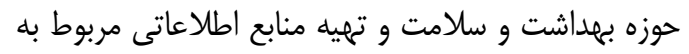

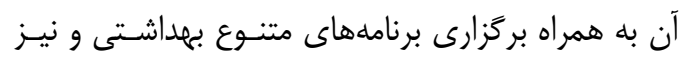

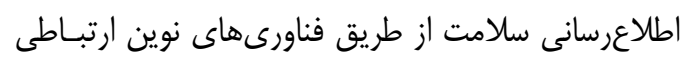

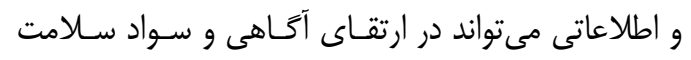

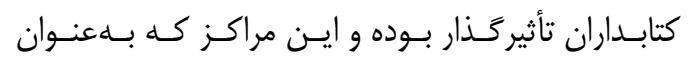

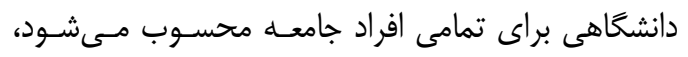

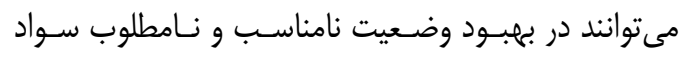
سلامت جامعه نقش آفرين باشد.

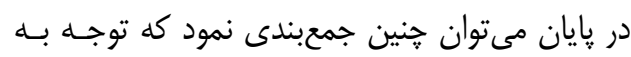

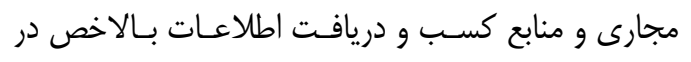

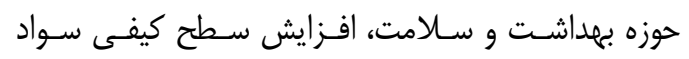

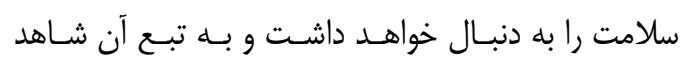

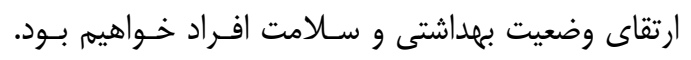

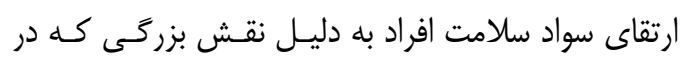

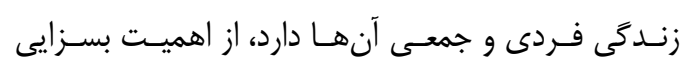

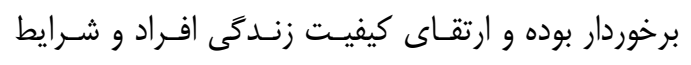

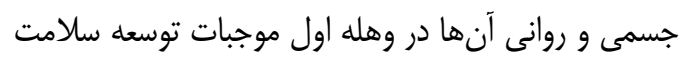
و پِس از آن توسعه اقتصادى، فرهنكى و اجتماعى كشـور را فراهم خواهد نمود.

\section{مقاس}

مقالـه حاضـر منتج از طـرح تحقيقاتـى اداره كــلـ

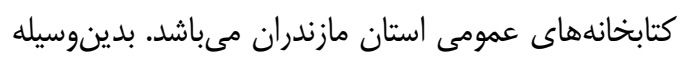

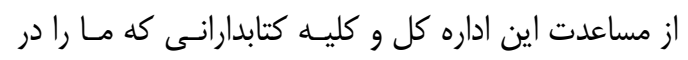

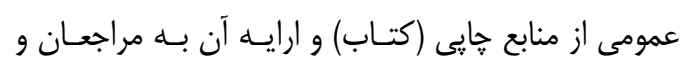

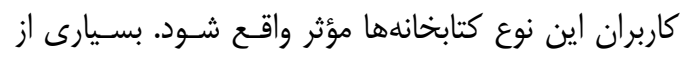

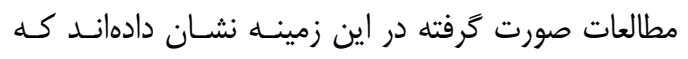

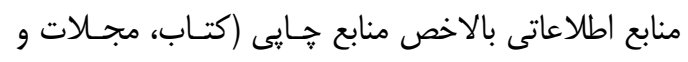

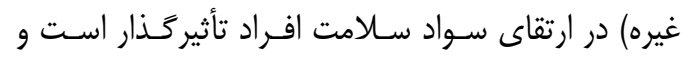

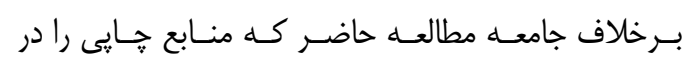

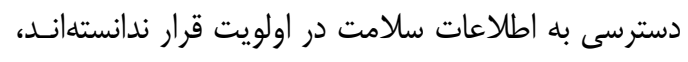

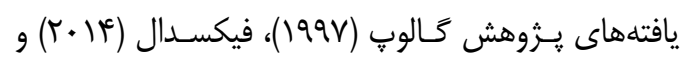

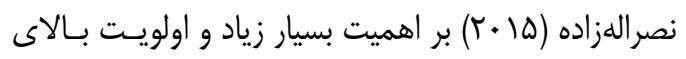

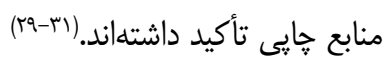
بلهعلاوه، نتايج همبستخى مثبت و معنسى دارى ميـان

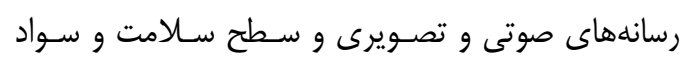

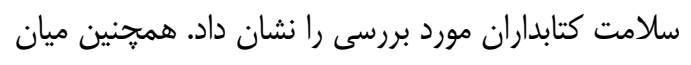

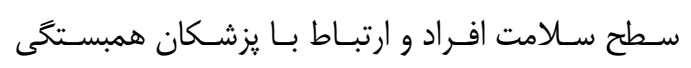

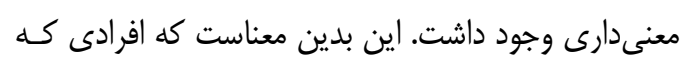

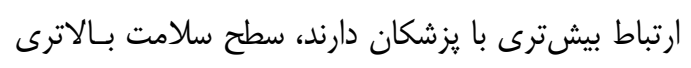

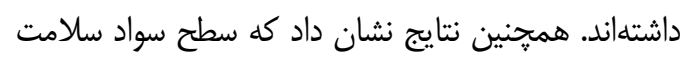

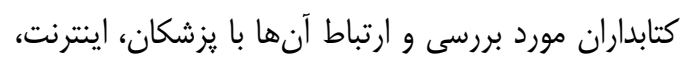

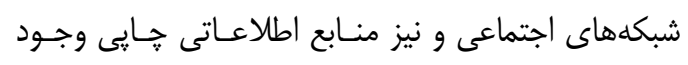
داشته است. همجنين همبستخى مثبت و معنى دارى ميان

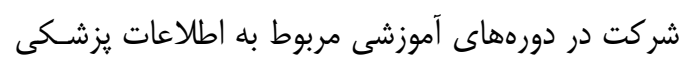

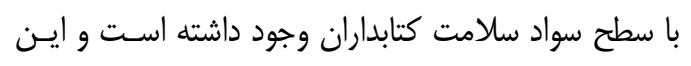
بدين معناست كه شركت در كلاسهاى آموزشى مىتواند

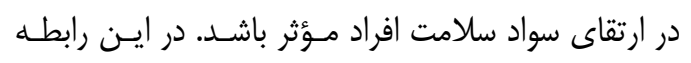

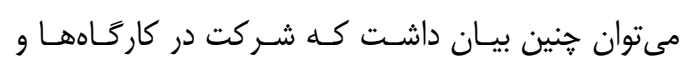

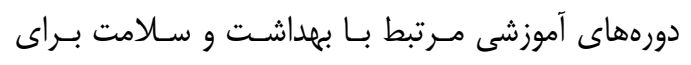

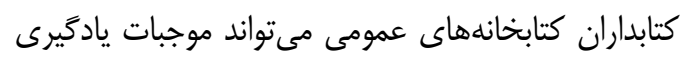

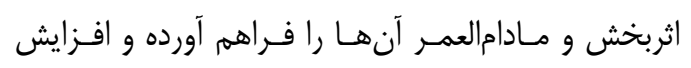

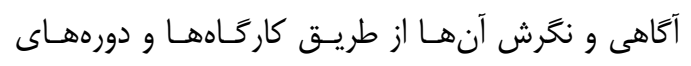

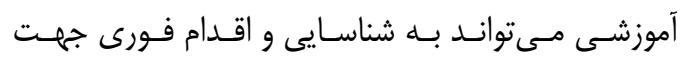

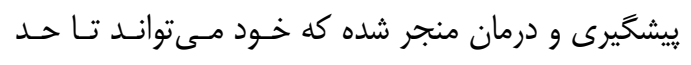

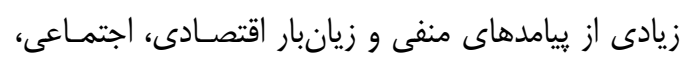
جسمى و روانى و ز... بكاهد. 
librarian to improve condition of Health in society. Lib Info Sci 2007; 9(4): 165-80.

8. Pournaghi R, Abazari Z. The survey study of information literacy between university librarians. J Health Adminstration 2008; 11(31): 55-62. [In Persian]

9. Ashrafi-Rizi H, Hodhodinezhad N, Shahrzadi L, Soleymani M. A study on the novel services of medical librarians in health information services: a narrative review. Health Info Manage 2017; 13(6): 438-44. [In Persian]

10. Parker R, Kreps GL. Library outreach: overcoming health literacy challenges. J Med Libr Assoc 2005 Oct; 93(4 Suppl): S81-5.

11. Raimondo PG, Harris RL, Nance M, Brown ED. Health literacy and consent forms: librarians support research on human subjects. J Med Libr Assoc 2014; 102(1): 5-8. doi: 10.3163/1536-5050.102.1.003.

12. Arndt TS. Health literacy: a natural role for librarians. Reference Services Review 2016; 44(2): 81-4. doi: 10.1108/RSR-042016-0026.

13. Riahi A, Hariri N, Nooshinfard F. Immigrants and information needs: health information needs of immigrants admitted to health care centers of medical sciences universities in Iran. J Health 2016; 7(4): 43545. [In Persian]

14. Choi N. Relationship between health service use and health information technology use among older adults: analysis of the US national health interview survey. $\mathrm{J}$ Med Internet Res 2011; 13(2): e33. doi: 10. 2196/jmir.1753.

15. Gray NJ, Klein JD, Noyce PR, Sesselberg TS, Cantrill JA. Health information-seeking behaviour in adolescence: the place of the internet. Soc Sci Med 2005; 60(7): 1467-78. doi: 10.1016/j.socscimed.2004.08.010.

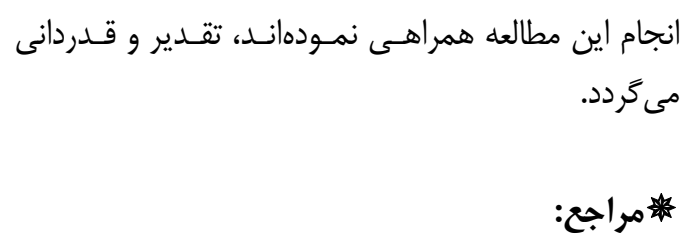

1. EsnaAshari F, Pirdehghan A, Rajabi F, Sayarifard A, Ghadirian L, Rostami N, et al . The study of health literacy of staff about risk factors of chronic diseases in 2014. J Hamadan Univ Med Sci 2015; 22(3): 248-54. [In Persian]

2. Izadirad H, Zareban I. The relationship of health literacy with health status, preventive behaviors and health services utilization in Baluchistan, Iran. J Edu Com Health 2016; 2(3): 43-50. doi: 10.20286/jech-02036. [In Persian]

3. Sahrayi M, Panahi R, Kazemi S, Rostami Z, Rezaei H, Jorvand R. The Study of Health Literacy of adults in Karaj. J Health Lite 2016; 1(4): 230-8.

4. Chen AM, Yehle KS, Albert NM, Ferraro KF, Mason HL, Murawski MM, Plake KS. Health literacy influences heart failure knowledge attainment but not self-efficacy for self-care or adherence to self-care over time. Nurs Res Pract. 2013; 24: 1-8. doi: 10.1155/2013/353290.

5. Ghanbari A, Rahmatpour P, Khalili M, Barari F. The association between health literacy and health status among the staff of Guilan University of Medical Sciences, Iran. J Health Syst Res 2016; 12(3): 381-7. [In Persian]

6. Tennant B, Stellefson M, Dodd V, Chaney B, Chaney D, Paige S, Alber J. eHealth literacy and Web 2.0 health information seeking behaviors among baby boomers and older adults. J Med Internet Res 2015; 17(3): e 70. doi: 10.2196/jmir.3992.

7. Sharif Moghadam H. The role of reference 
16. Cline RJ, Haynes KM. Consumer health information seeking on the Internet: the state of the art. Health Educ Res 2001; 16(6): 67192. doi: 10.1093/her/16.6.671.

17. Riahi A, Hariri N, Nooshinfard F. Study of health Information needs and barriers to access among afghan and iraqi immigrants in Iran. J North Khorasan Univ Med Sci 2015; 7(3): 597-610. doi: 10.29252/jnkums.7.3.597. [In Persian]

18. Brashers DE, Goldsmith DJ, Hsieh E. Information seeking and avoiding in health contexts. Hum Commun Res 2002; 28(2): 258-71. doi: 10.1111/j.1468-2958.2002.tb00 807.x.

19. Scanfeld D, Scanfeld V, Larson EL. Dissemination of health information through social networks: twitter and antibiotics. Am J Infect Control 2010; 38(3): 182-8. doi: 10. 1016/j.ajic.2009.11.004.

20. Ellis J, Mullan J, Worsley A, Pai N. The role of health literacy and social networks in arthritis patients' health information-seeking behavior: a qualitative study. Int J Family Med 2012; 10; 2012: 397039. doi: 10.1155/ 2012/397039.

21. Khodabakhshi-Koolaee A, Bahari M, Falsafinejad MR, Shahdadi H. The relationship of quality of life with health literacy in male patients with type II diabetes: a cross-sectional study in HARSIN city, 2015. J Diabetes Nurs 2016; 4(4): 10-20.

22. Meraji M, Rafat-Panah H, Mahmoodian S, Daeyan A. Assessment of university student health literacy toward Influenza. J Health Lit 2016; 1(3): 191-7. [In Persian]

23. Seyedoshohadaee $M$, Kaghanizade $M$, Nezami M, Hamedani B, Barasteh S. The relationship between health Literacy and general health in patients with type 2 diabetes. Iranian J Diabetes Metab 2016; 15(5): $312-319$

24. Nurss JR, Parker RM, Williams MV, Baker DW. TOFHLA: Test of functional health literacy in adults. Hartford MI: Peppercorn Books and Press Inc. USA: Snow Camp, NC; 2001. 9-19

25. Amini M, Mostafavizade M. Survey on Health Literacy of Librarians in Tehran University and Tehran University of Medical Sciences. Depict Health 2017; 7(4): 37-45. [In Persian]

26. Rubenstein EL. Health information and health literacy: Public library practices, challenges and opportunities. Public Libr Quarterly 2016; 35(1): 49-71. doi: 10.1080/ 01616846.2016.1163974.

27. Riahi A, Hariri N, Nooshinfard F. Health Information Needs of Immigrant Patients with Cancer in Iran. J Modern Med Inform Sci 2016; 2(1): 21-30. [In Persian]

28. Lambert SD, Loiselle CG. Health information seeking behavior. Qual Health Res 2007; 17(8): 1006-19. doi: 10.1177/ 1049732307305199.

29. Gollop CJ. Health information-seeking behavior and older African American women. Bull Med Libr Assoc 1997; 85(2): 141-6.

30. Fiksdal AS, Kumbamu A, Jadhav AS, Cocos C, Nelsen LA, Pathak J, et al. Evaluating the process of online health information searching: a qualitative approach to exploring consumer perspectives. J Med Internet Res 2014; 16(10): e224. doi: 10. 2196/jmir.3341.

31. Nasrollahzadeh S. Health informationseeking behavior of pregnant women: a grounded theory study. Human Info Intract 2015; 1(4): 270-81. [In Persian] 